\title{
Mitochondrial Abnormalities of Liver in Primary Ornithine Transcarbamylase Deficiency
}

\author{
J. M. SHAPIRO, F. SCHAFFNER, ${ }^{(2 N)}$ H. H. TALLAN, AND G. E. GAULL \\ Division of Liver Diseases of the Department of Medicine, Department of Pediatrics, Division of Human Genetics and \\ Clinical Research Center, Mount Sinai School of Medicine of the City. University of New York, and the Department of \\ Human Development and Nutrition of the New York State Institute for Basic Research in Mental Retardation. Staten \\ Island, New York, USA
}

\section{Summary}

Deficiency of hepatic ornithine transcarbamylase (EC 2.1.3.3) activity in a 17-month-old female patient is described. Enzyme activity was $11 \%$ of the mean control value. Electron microscopic examination of the liver specimen, taken by percutaneous needle biopsy, revealed striking abnormalities of the mitochondria: budlike projections, sausage-link appearance, elongation with short cristae, or the presence of parallel arrays of tubules. These abnormalities do not resemble those seen in Reye's syndrome.

\section{Speculation}

Abnormalities of the liver mitochondria in patients with ornithine transcarbamylase deficiency have not previously been observed. The specificity of these abnormalities requires study of further cases.

Primary ornithine transcarbamylase (OTC) (EC 2.1.3.3.) deficiency is the most frequent heritable disorder of the urea cycle (see Ref. 23 for review). It is inherited as an X-linked dominant disease (24). In the hemizygous male patient, it manifests itself shortly after birth by lethargy and poor feeding and progresses rapidly to seizures, coma, and often death; OTC activity is virtually absent. In the heterozygous female patient, the clinical manifestations characteristically occur later and vary widely from simple aversion to protein-rich food to recurrent severe episodes of hyperammonemia such as occur in the affected male patients. Secondary OTC deficiency, accompanied by carbamylphosphate synthetase (EC 2.7.2.2) deficiency, occurs in patients with Reye's syndrome (23).

Pathological changes in the liver of patients with primary OTC deficiency often have not been seen, either by gross examination or microscopically $(4,7,9,12,14,21,22)$; there are reports, on the other hand, of glycogen deposition $(3,10,26)$, fine fatty degeneration $(6,10,17,21)$, increased fibrous tissue (15), or minor steatosis and focal cell dropout and inflammation (12). In the brain, proliferation or enlargement of astrocytes $(4,10,14)$ and the presence of Alzheimer type II cells $(3,4)$ have been noted. There are two reports in abstract which describe electron microscopic examination of liver from affected individuals. Latham et al. (13) found an essentially normal picture in two cases; Hug et al. (11) (number of cases not stated) reported glycogen deposits, autophagic vacuoles, and abnormal microbodies, but apparently normal mitochondria. The present study, however, documents unusual changes in the mitochondria in a clinically typical, affected female at a time shortly after a severe episode when she was in good dietary control and only slight hyperammonemia was present.

\section{CASE REPORT}

The patient, born at term of a primagravida, healthy mother was fed a $1.5 \mathrm{~g} \%$ protein (casein-predominant) formula and was apparently well until 6 months of age. At that time, skimmed cow's milk was introduced, and there was "cyclical vomiting" for the next 7 months, during which time numerous dietary changes were used. At 15 months of age, there was a major motor seizure associated with fever, and in another hospital, she was placed on phenobarbital and sent home. After returning home, she became increasingly ataxic, lethargic, and irritable, and the vomiting increased. She was admitted to a second hospital for 4 days and discharged 4 days prior to her admission to the Mount Sinai Hospital at 17 months of age. At this time she was stuporous, urine $\mathrm{pH}$ was 9 , blood $\mathrm{pH}$ was 7.48 with a base excess of -9.9 $\mathrm{mEq} /$ liter, blood $\mathrm{NH}_{3}$ was $165 \mu \mathrm{g} / 100 \mathrm{ml}$ (normal $=<50$ ), serum glutamic-oxaloacetic transaminase was $102 \mathrm{mU} / \mathrm{ml}$ (normal = $<50$ ), serum glutamic-pyruvic transaminase was $87 \mathrm{mU} / \mathrm{ml}$ (nor$\mathrm{mal}=<53$ ), and there were abnormally increased plasma concentrations of glutamine, alanine, and glycine. Intermittent orotic aciduria (up to $276 \mu \mathrm{g} / \mathrm{mg}$ creatinine) was identified by the method of Bellinger and Buist (1); examination of urine by gas chromatography-mass spectrometry (25) demonstrated large amounts of pyruvate and 2-oxoglutarate but no unusual organic acids. Following reduction in protein intake, both the neurological and biochemical abnormalities responded rapidly toward normal. Satisfactory somatic growth without hyperammonemia was soon attained on a normal diet providing $1.8 \mathrm{~g}$ protein per $\mathrm{kg}$ per day. The patient had been receiving this diet for 10 days at the time of percutaneous liver biopsy. Venous blood ammonia concentration was then $84 \mu \mathrm{g} / 100 \mathrm{ml}$, plasma glutamine concentration was 242 $\mu$ moles $/ 100 \mathrm{ml}$ (normal $=<110)$, and plasma alanine concentration was $27 \mu$ moles $/ 100 \mathrm{ml}($ normal $=22$ to 43$)$.

The mother, who was in excellent health and had no history of protein intolerance, had no hyperammonemia or orotic aciduria even following a massive protein load $(1 \mathrm{~g} / \mathrm{kg}$ eggs, cheese, ham, and milk); urinary orotic acid (1) was $17.6 \mu \mathrm{g} / \mathrm{mg}$ creatinine in the $12 \mathrm{hr}$ preceding the load and $14.2 \mu \mathrm{g} / \mathrm{mg}$ creatinine in the $12 \mathrm{hr}$ following the load. A liver biopsy specimen was obtained from the mother on the day prior to this load. Written informed consent was obtained for liver biopsy both of mother and of patient.

\section{METHODS}

Liver specimens were homogenized with 19 volumes of ice-cold distilled water in a glass homogenizer. The assay procedure for ornithine transcarbamylase was a modification of that of Brown and Cohen (2), using conditions optimal for human liver: $10 \mathrm{mM}$ L-ornithine, $20 \mathrm{mM}$ dilithium carbamyl phosphate, and $180 \mathrm{mM}$ glycylglycine buffer ( $\mathrm{pH} \mathrm{8.3)}$ plus homogenate in a total volume of $250 \mu \mathrm{l}$. After incubation for $15 \mathrm{~min}$ at $37.5^{\circ} \mathrm{C}$, the reaction was stopped with trichloroacetic acid, and the citrulline formed was measured by the method of Prescott and Jones (20). Carbamylphosphate synthetase was assayed by a modification of the Brown and Cohen (2) procedure in which the following were incubated for $15 \mathrm{~min}$ at $37.5^{\circ} \mathrm{C}$ in a total volume of $1.0 \mathrm{ml}: 50 \mathrm{mM}$ glycylglycine $(\mathrm{pH} 7.6), 50 \mathrm{mM} \mathrm{NH} \mathrm{NCO}_{3}, 5 \mathrm{mM}$ dipotassium ATP, $3 \mathrm{mM} \mathrm{MgSO}, 5 \mathrm{mM}$ acetylglutamate, and homogenate. 


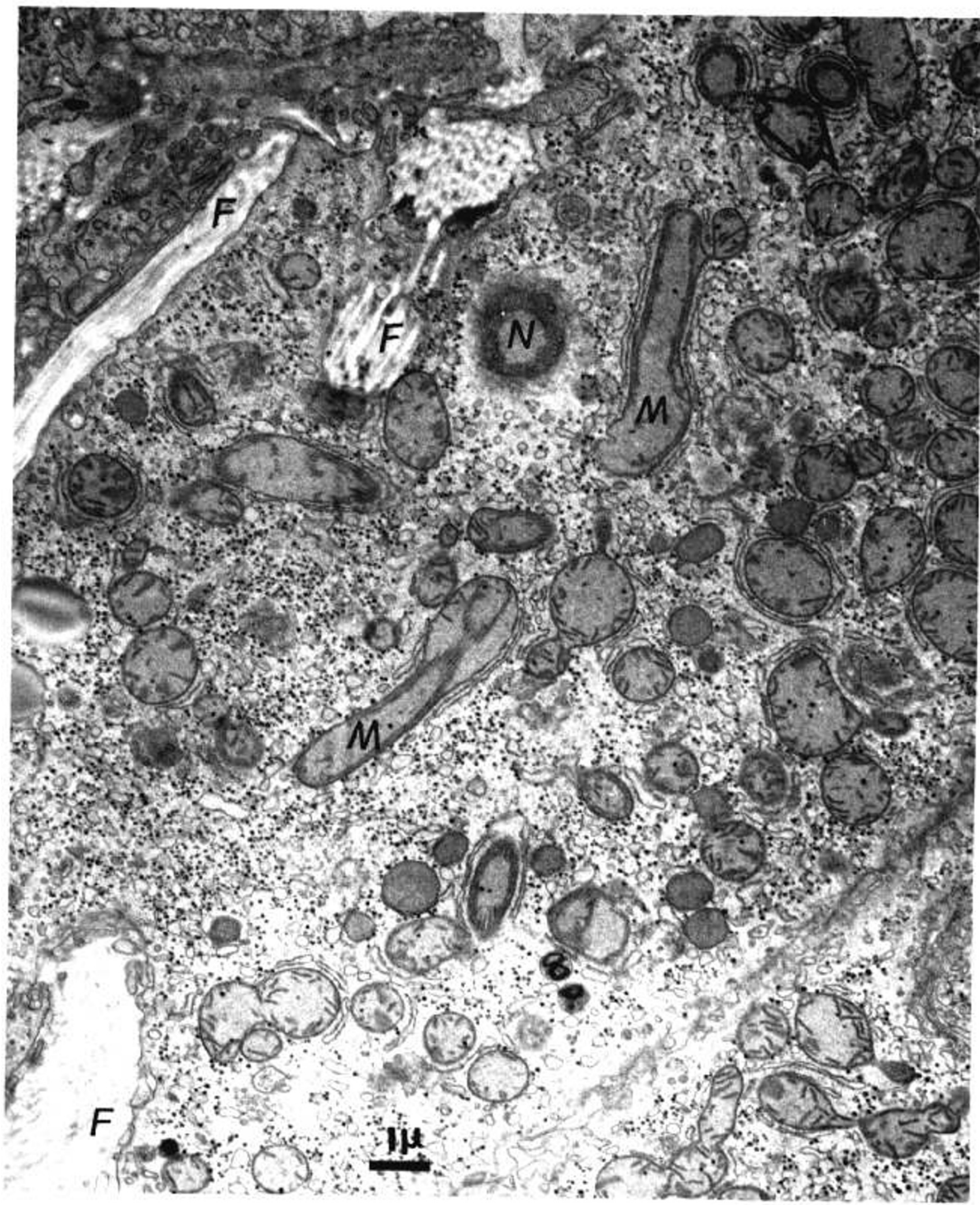

Fig. 1. Electron micrograph of liver biopsy specimen of patient described, showing a portion of hepatocyte containing mitochondria with paralle tubule formation $(M)$, seen on cross-section to be just under the inner membrane (arrow). Bundles of collagen fibers $(F)$ around the cell and mitochondria in the lower right corner which appear like sausage links. Also note the abundance of smooth endoplasmic reticulum throughout, and in many cells, the mitochondria with short cristae not directed toward the center of each mitochondrion. $N$ is a portion of the nucleus tangentially cut.
(Osmium fixed, uranyl and lead stained) $\times 10,000$. 
The carbamylphosphate formed was measured by the colorimetric method of Levine and Kretchmer (16); values were corrected for recovery as described (16). Erythrocytes were sedimented from heparinized whole blood, washed with saline, and lysed with water. Argininosuccinate lyase (EC 4.3.2.1) activity was determined as described by Fleisher $e t$ al. (8).

Part of each biopsy specimen, obtained with a $1.4-\times 70-\mathrm{mm}$ Menghini needle, was immediately placed in $2 \mathrm{ml}$ of ice-cold $1 \%$ osmium tetroxide in $s$-collidine buffer, where it remained for two hr. Each was then dehydrated in graded alcohol and embedded in Epon 812 . One-micron sections were cut and stained with toluidine blue. Ultrathin sections were cut by an LKB 111 Ultratome and stained with lead citrate. The specimens were viewed with a Hitachi HS8F electron microscope and compared with specimens obtained from previous patients with various metabolic disorders.

\section{RESULTS}

OTC activity was $11 \%$ of mean control in the patient and was $50 \%$ of mean control in the mother (Table 1). Other enzymes of the urea cycle had normal activity in both the patient and the mother (Table 1).

In the affected patient, the light microscopic sections showed slight increases in collagen and fat. Under the electron microscope, more striking abnormalities are observed (Fig. 1). The mitochondria in most of the cells, particularly in the centrolobular zone, are grossly misshapen. Most have projections that suggest budding of division; some appear like sausage links. In some elongated

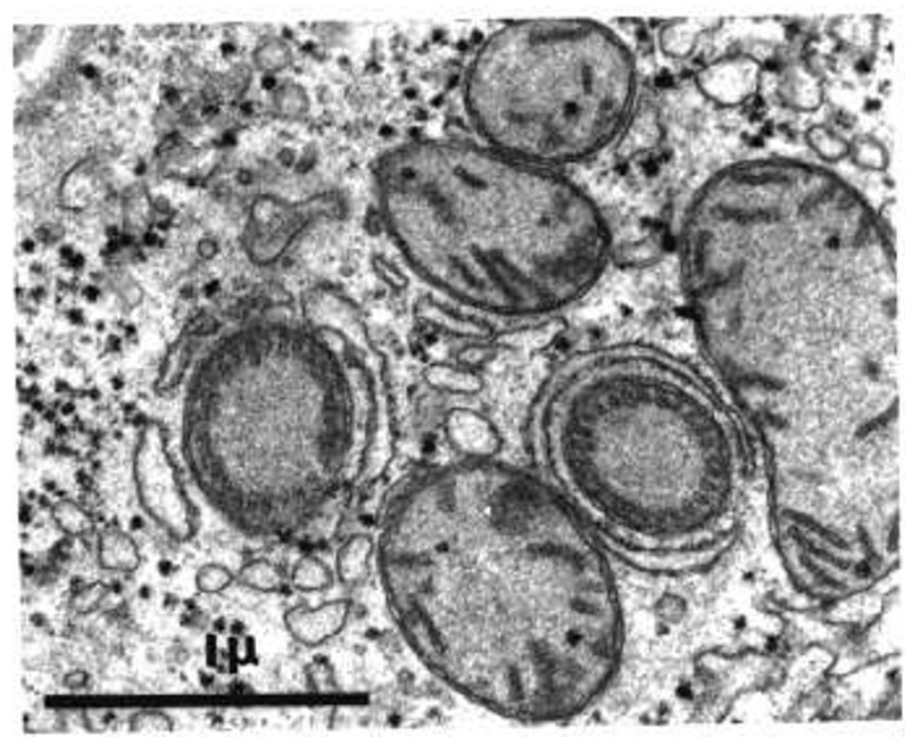

Fig. 2. Portion of Figure 1, showing mitochondrial tubules about 50 $\mathrm{nm}$ in diameter just beneath the inner membrane. $\times 40,000$. mitochondria, in about $20 \%$ of cells, the cristae are short, straight, and project less than one-half the usual distance towards the center of the mitochondria. Approximately 10 to 20 mitochondria in these same cells have parallel arrays of tubules in part of or throughout their circumference just beneath the inner membrane. These tubules are in only $10 \%$ of the cells, are about $50 \mathrm{~nm}$ in diameter (Fig. 2), are not mitochondrial crystalloid structures, and can be seen in longitudinal and in cross-sections. Other ultrastructural abnormalities include: increased numbers of microbodies with variation in size, increased amount of smooth endoplasmic reticulum in most cells, and the abnormalities observed under light microscopy, i.e., increased perisinusoidal collagen and hepatocellular fat. There were no abnormalities identified in the liver of the mother either by light or electron microscopy (Fig. 3).

\section{DISCUSSION}

OTC deficiency is a defect in the enzyme that couples carbamyl phosphate and ornithine to form citrulline (23). This reaction takes place in hepatocytic mitochondria (19) and is the second step in the cycle by which ammonia is transformed to urea. Inasmuch as the biochemical reaction catalyzed by the deficient enzyme occurs in the mitochondria, structural abnormality of the mitochondria is not totally unexpected. The proximate cause of the mitochondrial abnormalities is not clear. It is unlikely that the precursors of the reaction, namely carbamyl phosphate and ornithine, are at fault because there is no evidence that either builds up in the plasma. Carbamyl phosphate enters the cytoplasm, where it combines with aspartate to form orotic acid, a pyrimidine precursor (18); ornithine is either decarboxylated to putrescine or transaminated to glutamate (5). Although ammonia was not present in blood in strikingly high concentration at the time of biopsy, the increased plasma concentration of glutamine provides indirect evidence of an increased ammonia concentration in the liver (5); however, it is not a likely pathogenic factor itself because it is increased in Reye's syndrome (see below).

The absence of mitochondrial abnormalities in liver from the OTC-deficient patients of Latham et al. (13) and of Hug et al. (11) may be a reflection of the presence of normal ammonia concentrations in the period before biopsy. However, this can only be speculated upon until the full reports are available. In any event, not enough cases have yet been studied by electron microscopy to establish the typical cellular ultrastructure in primary OTC deficiency; it is hoped that such studies will be undertaken as new cases are diagnosed.

The investigations of Latham et al. (13) and of Hug et al. (11) were carried out to compare the findings in primary OTC deficiency and in primary carbamylphosphate synthetase deficiency with those in Reye's syndrome, in which the activity of both these enzymes is secondarily decreased. Although we now have found mitochondrial abnormalities in a case of isolated OTC deficiency (whereas they did not), the changes we observed do not resemble those described for Reye's syndrome $(11,13)$.

Table 1. Urea cycle enzymes in liver and blood

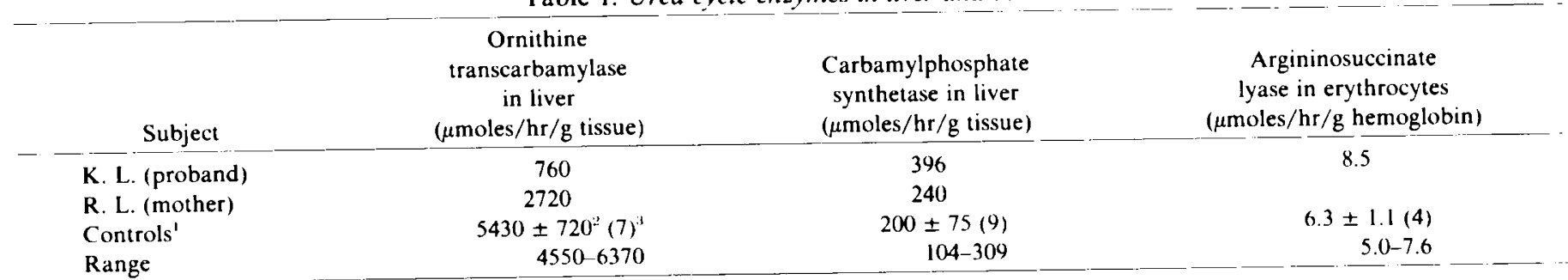

${ }^{1}$ Control liver was obtained at autopsy; ages ranged from neonatal to adult.

Mean \pm S.D.

${ }^{3}$ Numbers in parentheses, number of controls. 


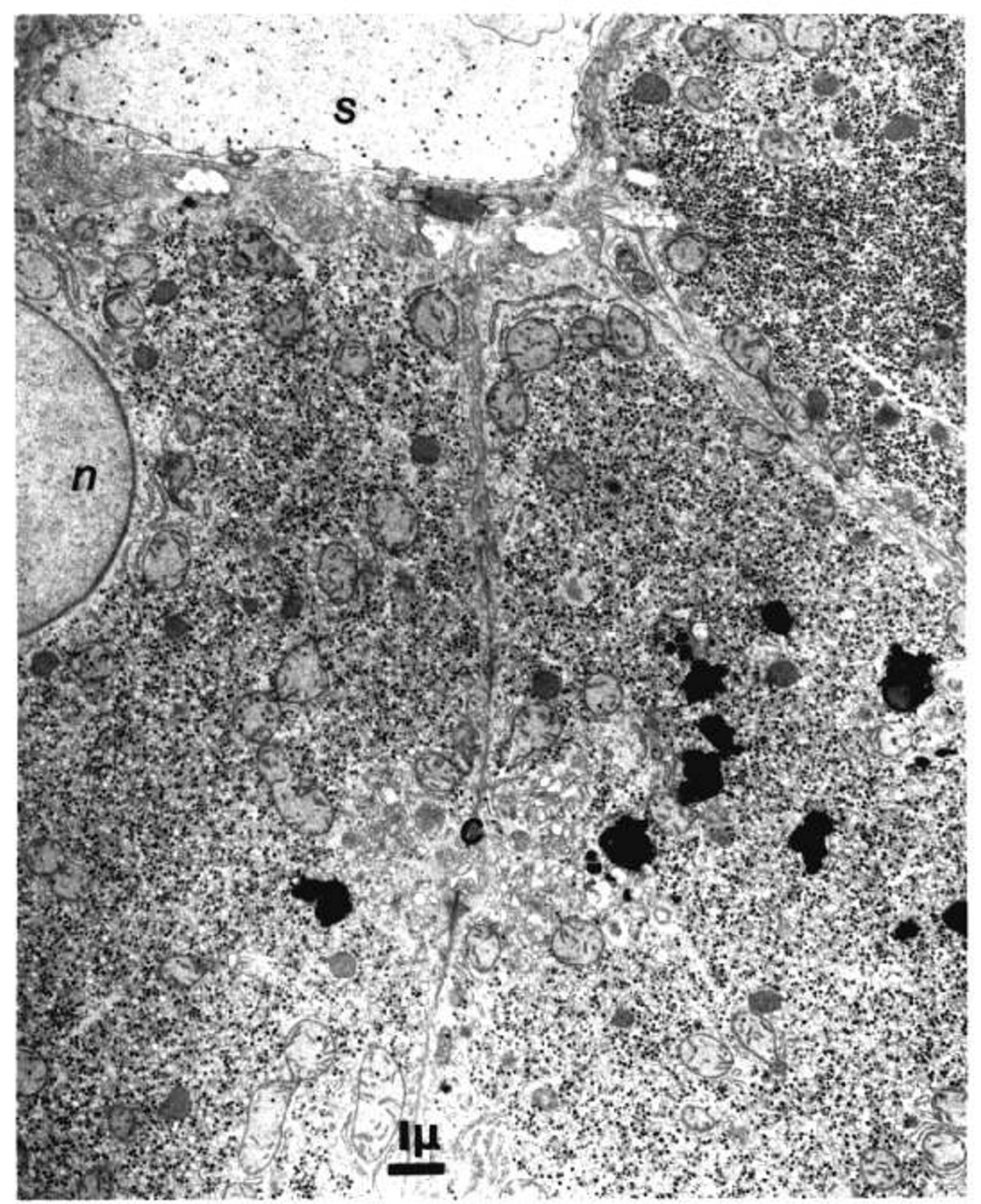

Fig. 3. Electron micrograph of liver biopsy specimen of mother, showing no abnormalities. $S$, sinusoid: $n$, nucleus; $c$, canaliculus. $\times 8000$.

\section{REFERENCES AND NOTES}

1. Bellinger, J. F., and Buist, N. R. M.: Rapid column-chromatographic measurement of orotic acid. Clin. Chem.. 17: 1132 (1971).

2. Brown, G. W., Jr., and Cohen, P. P.: Comparative biochemistry of urea synthesis. I. Methods for the quantitative assay of urea cycle enzymes in liver. J. Biol. Chem.. 234: 1769 (1959).

3. Bruton, C. J., Corsellis, J. A. N., and Russell, A.: Hereditary hyperammonaemia. Brain, 93: 423 (1970).

4. Campbell. A. G. M.. Rosenberg, L. E., Snodgrass, P. J., and Nuzum, C. T. Ornithine transcarbamylase deficiency. A cause of lethal neonatal hyperammonemia in males. N. Engl. J. Med., 288: 1 (1973).

5. Colombo, J. P.: Congenital disorders of the urea cycle and ammonia detoxication Monogr. Paediatr., I: 55 (1971).

6. Corbeel, L. M., Colombo, J. P. Van Sande, M., and Weber, A. Periodic attacks of lethargy in a baby with ammonia intoxication due to a congenital defect in ureogenesis. Arch. Dis. Child., 44: 681 (1969).

7. Farriaux, J. P., Dhondt, J. L., Cathelineau, L.. Ratel, J., and Fontaine, G. Hyperammonemia through deficiency of ornithine carbamyl transferase. $Z$. Kinderheilkd., 118: 231 (1974).

8. Fleisher, L. F., Rassin, D. K., Desnick, R. J., Salwen, H. R., Rogers, P., Bean.
M., and Gaull. G. E.: Arginosuccinic aciduria: prenatal studies in a family at risk. Am. J. Hum. Genet., 31: 439 (1979).

9. Goldstein, A. S., Hoogenraad, N. J., Johnson. J. D., Fukanaga, K. Swierczewski, E., Cann, H. M., and Sunshine, P.: Metabolic and genetic studies of a family with ornithine transcarbamylase deficiency. Pediatr. Res.. 8: 5 (1974).

10. Hopkins, I. J., Connelly, J. F., Dawson, A. G., Hird, F. J. R., and Maddison, T G.: Hyperammonaemia due to ornithine transcarbamylase deficiency. Arch. Dis. Child., 44: 143 (1969)

11. Hug, G. Kline, J., and Schubert, W.: Liver ultrastructure: dissimilarity between Reye's syndrome and heritable defect of carbamyl phosphate synthetase or ornithine transcarbamylase. Pediatr. Res. (Abstract), 12: 437 (1978).

12. LaBrecque, D. R., Latham, P. L., Riely, C. A., Hsia, Y. E., and Klatskin, G. R Liver pathology in inherited urea cycle enzyme deficiency states contrasted with that in Reye syndrome. Gastroenterology (Abstract), 73: 1230 (1977).

13. Latham, P. S., LaBrecque, D. R., Kashgarian. M. and Klatskin G.: A comparative ultrastructural study of inherited urea cycle enzyme deficiency states and Reye's syndrome. Gastroenterology (Abstract), 73: 1230 (1977).

14. Levin, B., Abraham, J. M., Oberholzer, V. G., and Burgess, E. A.: Hyperam monaemia: a deficiency of liver ornithine transcarbamylase. Occurrence in mother and child. Arch. Dis. Child., 44: 152 (1969).

15. Levin, B., Dobbs, R. H., Burgess, E. A., and Palmer, T.: Hyperammonaemia. A 
variant type of deficiency of liver ornithine transcarbamylase. Arch. Dis. Child., 44: 162 (1969).

16. Levine. R. L., and Kretchmer. N.: Conversion of carbamoyl phosphate to hydroxyurea. An assay for carbamoylphosphate synthetase. Anal. Biochem. 42: 324 (1971).

17. Matsuda, I., Arashima. S., Nambu, H., Takekoshi, Y., and Anakura, M.: Hyperammonemia due to a mutant enzyme of ornithine transcarbamylase. Pediatrics. 48: 595 (1971).

18. Natale, P. J., and Tremblay, G. C.: On the availability of intra-mitochondrial carbamylphosphate for the extramitochondrial synthesis of pyrimidines. Biochem. Biophys. Res. Commun., 37: 512 (1969).

19. Pierson, D. L., Cox, S. L., and Gilber, B. E.: Human ornithine transcarbamylase J. Biol. Chem., 252: 6464 (1977).

20. Prescott. L. M., and Jones, M. E.: Modified methods for the determination of carbamyl aspartate. Anal. Biochem., 32: 408 (1969).

21. Ricciuti, F. C., Gelehrter, T. D., and Rosenberg, L. E.: X-Chromosome inactivation in human liver: confirmation of X-linkage of ornithine transcarbamylase. Am. J. Hum. Genet.. 28: 332 (1976).

22. Saudubray, J. M., Cathelineau, L.. Charpentier, C., Boisse. J., Allaneau, C., LeBont. H., and Lesage. B.: Defficit héreditaire en ornithine-carbamyl-transférase avec anomalie enzymatique qualitative. Arch. Fr. Pediatr.. 30: 15 (1973).

23. Shih, V. E.: Urea cycle disorders and other congenital hyperammonemic syndromes. In: J. B. Stanbury, J. B. Wyngaarden. D. S. Frederickson: The

Copyright (1) 1980 International Pediatric Research Foundation, Inc. $0031-3998 / 80 / 1405-0735 \$ 02.00 / 0$
Metabolic Basis of Inherited Disease. p. 352 (McGraw-Hill Book Co.. New York, 1978)

24. Short, E. M., Conn, H. O.. Snodgrass, P. J., Campbell, A. G. M., and Rosenberg. L. E.: Evidence for $\mathrm{X}$-linked dominant inheritance of ornithine transcarbamylase deficiency. N. Engl. J. Med., 288: 7 (1973).

25. Sternowsky, H. J., Roboz, J., Hutterer, F., and Gaull, G.: Determination of $\alpha$ keto acids as silylated oximes in urine and serum by combined gas chromatography-mass spectrometry. Clin. Chim. Acta. 47: 371 (1973).

26. Sunshine. P., Lindenbaum, J. E., Levy, H. L., and Freeman. J. M.: Hyperammonemia due to a defect in hepatic ornithine transcarbamylase. Pediatrics, 50: 100 (1972).

27. The authors are grateful to Drs. Donald Gribetz and Alan Aron of the Mount Sinai Hospital, who made the presumptive diagnosis of OTC deficiency on clinical grounds alone; to Dr. Laszlo Sarkozi for repeated rapid blood ammonia determinations: to our nutritionists, Diane Lieberman and Marcia Kalin; and to Lydia Castellar and Karmela Schneidman for excellent technical assistance. 28. Requests for reprints should be addressed to: F. Schaffner. M. D.. Department of Medicine. The Mount Sinai Hospital, Gustave L. Levy Plaza. New York. N. Y. 10029 (USA).

29. This research was supported by Clinical Research Center Grant FR-0007I and by the New York State Department of Mental Hygiene.

30. Received for publication January 22, 1979.

31. Accepted for publication August 21, 1979. 